\title{
Management of complex renal cysts in Canada: results of a survey study
}

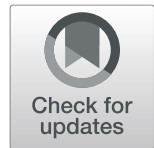

\author{
Félix Couture ${ }^{1}$, Antonio Finelli', Amélie Tétu ${ }^{3}$, Bimal Bhindi ${ }^{4}$, Rodney H. Breau ${ }^{5}$, Anil Kapoor ${ }^{6}$, Wassim Kassouf ${ }^{7}$, \\ Luke Lavallée ${ }^{5}$, Simon Tanguay ${ }^{7}$, Philippe D. Violette ${ }^{8}$ and Patrick O. Richard ${ }^{1 *}$
}

\begin{abstract}
Background: Bosniak III and IV cysts have a high risk of malignancy and have traditionally been managed surgically. However, growing evidence suggests that many can be managed by active surveillance. The main objective of this study was to characterize the use of surveillance in the management of complex renal cysts.

Methods: A web-based survey was sent to all registered, active members of the Canadian Urological Association $(N=583)$ in October 2018.

Results: The survey response rate was $24.7 \%$. Management of Bosniak III cysts varied considerably. A large proportion of respondents (33.1\%) offered active surveillance in $>50 \%$ of cases. Only $13.7 \%$ of respondents reported never or rarely (<5\% of cases) offering surveillance. In contrast, for Bosniak IV cysts, $60.1 \%$ of urologists never or rarely offered surveillance, while only $10.1 \%$ offer it in $>50 \%$ of cases. A significantly greater proportion of academic urologists, compared to non-academic urologists, viewed surveillance as a management option for patients with a Bosniak III or IV cyst. The most commonly reported barriers to a greater adoption of surveillance were concerns regarding its oncologic safety, the lack of data to support surveillance in this population, and the lack of triggers for discontinuation of active surveillance and intervention.

Conclusions: Despite active surveillance being included as a management option in guidelines, many Canadian urologists are reluctant to offer surveillance to patients with Bosniak III or IV cysts. Practice patterns are heterogeneous among those offering surveillance. High-quality studies are required to better define the benefits and risks of cystic renal mass surveillance.
\end{abstract}

Keywords: Complex renal cysts, Bosniak, Active surveillance, Surgery, Management

\section{Background}

Up to one third of individuals over 60 years of age will be diagnosed with a renal cyst following abdominal imaging [1]. Renal cysts are classified according to the Bosniak classification, which categorizes the cysts according to their degree of complexity and risk of malignancy [2-4]. Cystic renal cell carcinoma represents approximately $5-10 \%$ of all renal malignancies [5]. Bosniak III and IV cysts have a high risk of

\footnotetext{
* Correspondence: patrick.richard@usherbrooke.ca

'Division of Urology, Department of Surgery, Centre Hospitalier Universitaire de Sherbrooke, 3001, 12e avenue N, Sherbrooke, Quebec J1H 5N4, Canada Full list of author information is available at the end of the article
}

malignancy (40-60\% and 80-90\%, respectively) and have traditionally been managed with surgical excision [6, 7]. However, similar to small non-cystic renal masses, there is growing evidence suggesting that most of these cysts are indolent and unlikely to metastasize $[5,8-15]$. Thus, active surveillance has been proposed as an alternative to surgery $[6,16]$.

Recent observational data has provided support for the use of active surveillance among patients with complex renal cysts $[17,18]$. However, the adoption of this treatment strategy for the management of complex cysts in Canada and the criteria used by urologists as triggers for discontinuation of surveillance and intervention have yet to be defined.

C C The Author(s). 2020 Open Access This article is licensed under a Creative Commons Attribution 4.0 International License, which permits use, sharing, adaptation, distribution and reproduction in any medium or format, as long as you give appropriate credit to the original author(s) and the source, provide a link to the Creative Commons licence, and indicate if changes were made. The images or other third party material in this article are included in the article's Creative Commons licence, unless indicated otherwise in a credit line to the material. If material is not included in the article's Creative Commons licence and your intended use is not permitted by statutory regulation or exceeds the permitted use, you will need to obtain permission directly from the copyright holder. To view a copy of this licence, visit http://creativecommons.org/licenses/by/4.0/ The Creative Commons Public Domain Dedication waiver (http://creativecommons.org/publicdomain/zero/1.0/) applies to the data made available in this article, unless otherwise stated in a credit line to the data. 
The objectives of this survey study were to characterize the use of active surveillance in the management of complex renal cysts in Canada and to elicit the perceived barriers to adoption. We also aimed to characterize patient and disease factors associated with use of active surveillance and triggers used as criteria for intervention.

\section{Methods}

This is a descriptive cross-sectional study using electronic surveys and conducted based on known guidelines [19, 20]. Following approval from the CIUSSS de l'Estrie - CHUS Research Ethics Board, a pilot questionnaire was developed and tested among 20 urologists in October 2018. All items were then revised according to the feedback received in the pilot survey. The survey questions were formatted as short answer, multiple choice, or Likert rating scale questions. Responses were anonymous and no personal information was collected or stored. An electronic open survey was generated on REDcap ${ }^{\mathrm{Tm}}$ and distributed via email. The survey was distributed to all active members of the Canadian Urological Association (CUA) with a functional email address. Three emails (one initial and two reminders) containing a link to the English language questionnaire were sent out to all 583 members between October 30 and November 19, 2018. Questions covered practice patterns regarding complex renal cysts, criteria used to select candidates for active surveillance, triggers to intervene in patients on active surveillance, and perceived barriers to a greater adoption of active surveillance (Additional file 1). In analyses, we excluded non-practicing urologists, urologists who reported not managing complex renal cysts, and urologists who gave incomplete demographic information or who did not answer questions beyond the demographic section.

Continuous and categorical variables were reported using medians (interquartile range $[\mathrm{IQR}]$ ) and proportions, respectively. Chi-squared tests were used to assess differences between specific groups of respondents (types of practice). Statistical analyses were conducted using SAS/STAT ${ }^{ø}$ software, version 9.4. All statistical tests were two-sided and $p$ values $<0.05$ were considered statistically significant.

\section{Results}

In total, 144 urologists (24.7\%) responded to the survey. From these, we excluded three urologists who were not actively in practice or did not manage complex cysts, and two urologists because they did not answer any questions other than demographics. Therefore, our study included 139 respondents, of which $88.8 \%(N=122)$ answered every survey question.

Demographic data are presented in Table 1. Of the eligible respondents, 71 (51.1\%) practiced in an academic center, while $68(48.9 \%)$ practiced in a non-academic setting. The majority (87.0\%) of respondents reported managing $\leq 20$ new complex renal cysts on an annual basis.
Table 1 Demographic data of the included respondents ( $N=$ 139)

\begin{tabular}{|c|c|}
\hline Variables & N (\%) \\
\hline \multicolumn{2}{|l|}{ Years in independent practice } \\
\hline$\bullet 1$ to 5 & $56(40.3)$ \\
\hline$\bullet 6$ to 10 & $29(20.9)$ \\
\hline • 11 to 15 & $21(15.1)$ \\
\hline$\bullet>15$ & $33(23.7)$ \\
\hline \multicolumn{2}{|l|}{ Fellowship training } \\
\hline -Urologic oncology & $46(33.1)$ \\
\hline •Endourology/Minimally invasive surgery & $30(21.6)$ \\
\hline • Other fellowship & $23(16.6)$ \\
\hline •No fellowship training & $40(28.8)$ \\
\hline \multicolumn{2}{|l|}{ Type of practice } \\
\hline -Academic hospital & $71(51.1)$ \\
\hline •Community or rural hospital & $66(47.5)$ \\
\hline - Office-based practice & $2(1.4)$ \\
\hline \multicolumn{2}{|l|}{ Area of practice } \\
\hline -British Columbia & $10(7.2)$ \\
\hline -Prairies & $18(13.0)$ \\
\hline •Ontario & $59(42.5)$ \\
\hline -Quebec & $43(30.9)$ \\
\hline -Atlantic Canada & $9(6.5)$ \\
\hline \multicolumn{2}{|c|}{ Annual number of new complex renal cysts cases (Bosniak III-IV) } \\
\hline$\bullet 1-5$ & $24(17.3)$ \\
\hline$\bullet 6-10$ & $42(30.2)$ \\
\hline$\bullet 11-20$ & 55 (39.6) \\
\hline$\bullet 21-30$ & $10(7.2)$ \\
\hline$\bullet>30$ & $8(5.8)$ \\
\hline
\end{tabular}

\section{Use of active surveillance}

Of the eligible respondents, $13.7 \%$ of urologists never or rarely ( $<5 \%$ of cases) offered active surveillance, while $33.1 \%$ offered active surveillance in $>50 \%$ of patients with a Bosniak III cysts in whom surgical excision is considered a suitable treatment option (Fig. 1). When compared to non-academic urologists, a significantly greater proportion of academic urologists offered active surveillance as a treatment option to their patients with a Bosniak III cyst. When patients with a Bosniak III cyst were offered active surveillance as a treatment option, it was perceived by nearly half of the urologists (45.7\%) that this option was accepted in a majority of cases. The likelihood of a patient accepting active surveillance for the management of a Bosniak III cyst was perceived to be significantly greater by urologists from academic centres than by urologists from non-academic centres.

Unlike for Bosniak III cyst, a majority of urologists $(60.1 \%)$ never or rarely ( $<5 \%$ of cases) offered active surveillance for Bosniak IV cysts, while only 10.1\% offered 


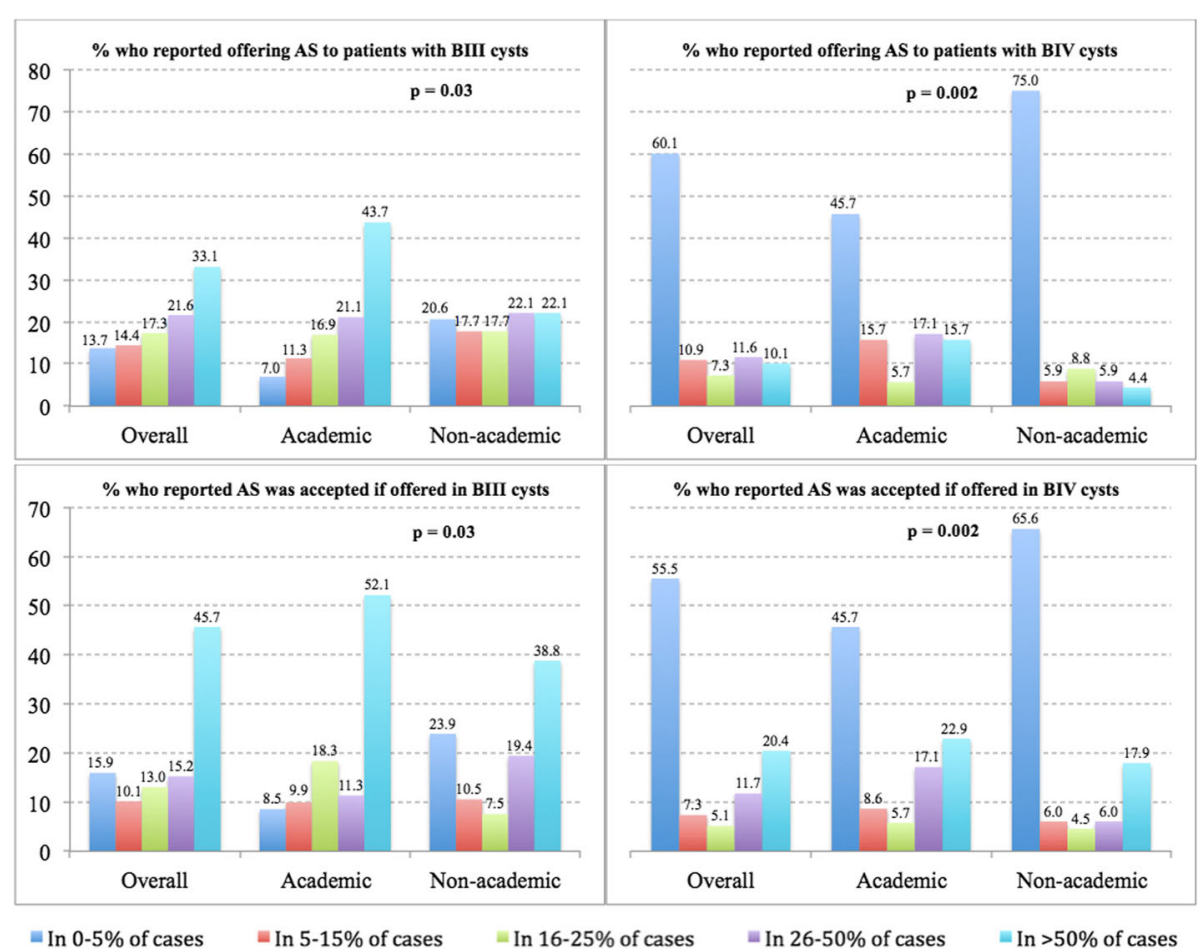

Fig. 1 Active surveillance use - Percentage of respondents who reported offering active surveillance (AS) to a certain proportion of patients and percentage of these patients they felt accept surveillance, for Bosniak III (BIII) and for Bosniak (BIV) cysts (overall and according to type of practice)

active surveillance in $>50 \%$ of cases. A significantly greater proportion of academic than non-academic urologists viewed active surveillance as a viable treatment alternative for patients with a Bosniak IV cyst. However, even when active surveillance was proposed to a patient as a treatment option, only $20.4 \%$ of urologists stated that this option was accepted by $>$ $50 \%$ of patients.

\section{Barriers to active surveillance adoption}

Several potential barriers to a greater adoption of active surveillance were noted (Table 2). The most commonly reported ones were [1] the patient's and physician's concerns regarding the oncologic safety and/or benefits of active surveillance (89.8\%), [2] the lack of data supporting active surveillance in patients with Bosniak III-IV cysts (74.2\%), and

Table 2 Perceived barriers to a more widespread adoption of active surveillance for Bosniak III-IV cysts $(N=128)$

\begin{tabular}{|c|c|c|c|}
\hline Concerns & $\begin{array}{l}\text { Disagree } \\
\text { N (\%) }\end{array}$ & $\begin{array}{l}\text { Neither agree nor } \\
\text { disagree } \\
\mathrm{N}(\%)\end{array}$ & $\begin{array}{l}\text { Agree } \\
N(\%)\end{array}$ \\
\hline 1) Patient and physician concerns regarding the oncologic safety and/or benefits of active surveillance. & $8(6.3)$ & $5(3.9)$ & $\begin{array}{l}114 \\
(89.8)\end{array}$ \\
\hline 2) The psychological burden for the physicians or patients & $33(25.8)$ & $29(22.7)$ & $\begin{array}{l}66 \\
(51.6)\end{array}$ \\
\hline $\begin{array}{l}\text { 3) The belief that active surveillance is not an appropriate alternative since an effective surgical option } \\
\text { already exists. }\end{array}$ & $43(33.6)$ & $31(24.2)$ & $\begin{array}{l}54 \\
(42.2)\end{array}$ \\
\hline 4) The lack of data to support active surveillance in patients with BIII-IV & $17(13.3)$ & $16(12.5)$ & $\begin{array}{l}95 \\
(74.2)\end{array}$ \\
\hline 5) The lack of specific triggers for intervention during active surveillance for cystic tumors & $11(8.6)$ & $20(15.6)$ & $\begin{array}{l}97 \\
(75.8)\end{array}$ \\
\hline $\begin{array}{l}\text { 6) The lack of guidance/knowledge/decision-aid tool on how to best manage and follow patients on active } \\
\text { surveillance }\end{array}$ & $22(17.2)$ & $30(23.4)$ & $\begin{array}{l}76 \\
(59.4)\end{array}$ \\
\hline $\begin{array}{l}\text { 7) The belief that active surveillance is not an efficient trade-off to surgery because it increases the burden } \\
\text { of care (i.e., more visits and repeated tests). }\end{array}$ & $69(53.9)$ & $36(28.1)$ & $\begin{array}{l}23 \\
(18.0)\end{array}$ \\
\hline 8) The reliability of patients and the possibility of patients being lost to follow-up on active surveillance. & $47(36.7)$ & $48(37.5)$ & $\begin{array}{l}33 \\
(25.8)\end{array}$ \\
\hline
\end{tabular}


[3] the lack of specific triggers for intervention during surveillance for complex renal cysts (75.8\%).

\section{Factors increasing likelihood of offering active surveillance}

For both Bosniak III and IV cysts, age and the presence of comorbidities were perceived as having an impact on the likelihood of a patient being offered active surveillance as a treatment alternative (Table 3). The majority of urologists viewed older patients ( $>75$ years of age) as being ideal candidates. Nevertheless, nearly $30 \%$ of urologists thought that the lower age cut-off should be 65 years old for patients with Bosniak III cysts. Likewise, most urologists viewed that cyst size influenced their decision to offer surveillance and that cysts $<4 \mathrm{~cm}$ were ideal for active surveillance.

More specifically, for Bosniak III cysts, the presence of cyst wall nodularity (74.8\%) and the maximal thickness of septa/calcification (44.1\%) were also considered characteristics that impacted the likelihood of offering active surveillance. An upper limit threshold of $3 \mathrm{~mm}$ (IQR 2$5 \mathrm{~mm}$ ) in maximal thickness of septa/calcification was perceived as being most appropriate for surveillance. For Bosniak IV cysts, the size of the nodular component was seen as important to the decision to offer active surveillance $(69.9 \%)$ with a median perceived upper limit cutoff of $2 \mathrm{~cm}$ (IQR $1-3 \mathrm{~cm}$ ).

\section{Triggers for intervention during active surveillance}

Several characteristics were perceived by urologists as being criteria for intervention for patients initially managed by active surveillance (Table 4). The most commonly reported criteria for Bosniak III cysts were [1] progression on imaging from Bosniak III to IV cysts, [2] worsening or change in the wall or septa enhancement, [3] progression or development of cyst wall nodularity. For Bosniak IV cysts, the two most common triggers for intervention were perceived as being [1] the growth rate of solid component ( $>0.5 \mathrm{~cm} /$ year) and [2] the growth of solid component $(>3 \mathrm{~cm})$.

\section{Surgical management}

When managed surgically, over half of respondents (57.3\%) were more likely to offer a minimally invasive

Table 3 Association of patient and tumor factors with likelihood of recommending active surveillance and specific cut-offs viewed as most appropriate for active surveillance ( $N=127$ for Bosniak III; $N=124$ for Bosniak IV)

\begin{tabular}{|c|c|c|}
\hline \multirow[b]{2}{*}{ Characteristics } & \multicolumn{2}{|c|}{$\begin{array}{l}\text { Significant impact on likelihood to recommend active surveillance reported } \\
N(\%)\end{array}$} \\
\hline & Bosniak III & Bosniak IV \\
\hline \multicolumn{3}{|l|}{ Patient factors } \\
\hline -Age & $121(95.3)$ & $104(84.5)$ \\
\hline \multicolumn{3}{|l|}{-Cutoff } \\
\hline$\circ>55$ years old & $6(5.0)$ & $3(2.9)$ \\
\hline $0>65$ years old & $35(28.9)$ & $17(16.4)$ \\
\hline $0>75$ years old & $80(66.1)$ & $84(80.8)$ \\
\hline -Presence of comorbidities & $121(96.0)$ & $105(85.4)$ \\
\hline \multicolumn{3}{|l|}{ Tumor factors } \\
\hline -Cyst size & $72(56.7)$ & $59(48.0)$ \\
\hline \multicolumn{3}{|l|}{-Cutoff } \\
\hline $0<4 \mathrm{~cm}$ & $56(77.8)$ & $54(91.5)$ \\
\hline $0<7 \mathrm{~cm}$ & $16(22.2)$ & $5(8.5)$ \\
\hline -Size of nodular component & N/A & $86(69.9)$ \\
\hline - Upper limit cutoff, median (IQR) & & $2 \mathrm{~cm}(1-3 \mathrm{~cm})$ \\
\hline -Number of septa/calcification & $32(25.2)$ & $25(20.7)$ \\
\hline \multicolumn{3}{|l|}{-Cutoff } \\
\hline $0 \leq 2$ & $7(22.9)$ & $9(36.0)$ \\
\hline $0 \leq 3$ & $20(62.5)$ & $12(48.0)$ \\
\hline $0 \leq 4$ or 5 & $5(15.7)$ & $4(16.0)$ \\
\hline -Thickness of septa/calcification & $56(44.1)$ & $31(25.2)$ \\
\hline - Upper limit cutoff, median (IQR) & $3 \mathrm{~mm}(2-5 \mathrm{~mm})$ & $5 \mathrm{~mm}(3-5 \mathrm{~mm})$ \\
\hline -Cyst wall nodularity & $95(74.8)$ & N/A \\
\hline
\end{tabular}


Table 4 Criteria perceived as being triggers for intervention

\begin{tabular}{|c|c|c|}
\hline \multirow[b]{2}{*}{ Characteristics } & \multicolumn{2}{|c|}{$\begin{array}{l}\text { Criterion reported as being a trigger for intervention } \\
\mathrm{N}(\%)\end{array}$} \\
\hline & Bosniak III & Bosniak IV \\
\hline Progression on imaging from Bosniak III to IV & $110(79.1)$ & N/A \\
\hline Growth rate of solid component above threshold (for example: $>0.5 \mathrm{~cm} /$ year) & N/A & $85(61.2)$ \\
\hline Growth of solid component above threshold (for example: > $3 \mathrm{~cm}$ ) & N/A & $88(63.3)$ \\
\hline Growth rate of cysts above threshold (for example: $>0.5 \mathrm{~cm} /$ year) & $48(34.5)$ & $28(20.1)$ \\
\hline Doubling time of calculated volume $\leq 12$ months & $39(28.1)$ & $39(28.1)$ \\
\hline Progression in the number of septa or calcifications & $29(20.9)$ & $28(20.1)$ \\
\hline Progression in the thickness of septa or calcifications & $60(43.2)$ & $43(30.9)$ \\
\hline Worsening or change in the wall or septa enhancement & $70(50.4)$ & N/A \\
\hline Progression or development of cyst wall nodularity & $94(67.6)$ & N/A \\
\hline None of the above & $2(1.4)$ & $3(2.2)$ \\
\hline I do not offer active surveillance & $1(0.7)$ & $25(18.0)$ \\
\hline
\end{tabular}

partial nephrectomy approach to patients with a complex cyst as the surgical management of choice. No significant differences in terms of surgical management were observed between academic and non-academic urologists (Additional file 2). When compared to the management of small non-cystic renal masses, the majority of surveyed urologists managed Bosniak III and IV cysts in a similar fashion to how they manage small non-cystic renal masses. However, 20.7\% of respondents were more inclined to offer an open surgical approach, while $14.6 \%$ were more inclined to perform a radical nephrectomy as opposed to a partial nephrectomy. Again, there were no statistically significant differences observed in the management of academic and community urologists (Additional file 3).

\section{Discussion}

Indirect evidence from the small non-cystic renal mass literature has supported the role of active surveillance as a management option for complex renal cysts [5, 8, 10, 11, 16, 21-24]. Two recent retrospective studies have also reported the outcomes of patients with a complex renal cyst who opted to be managed by active surveillance $[17,18]$. The average cyst sizes in the two studies were $4.1 \mathrm{~cm}$ and $3.5 \mathrm{~cm}$ for Bosniak III cysts, and $3.1 \mathrm{~cm}$ and $3.8 \mathrm{~cm}$ for Bosniak IV lesions, respectively. Both studies have suggested that this approach could be safely used in this population, with only one death due to kidney cancer observed after 5 years of follow-up in these studies. Moreover, only two patients with a Bosniak IV cyst developed a metastasis out of 243 patients with a Bosniak III or IV cyst $(0.8 \%)$ - both of whom had refused surgery despite evidence of local progression. Criteria for lesion progression included increase in cyst size, increase in vascularity, and increase in size of the solid component. Importantly, during the 5-year observation period, $65 \%$ of patients avoided surgery given the absence of lesion progression, and among patients who progressed, $16.5 \%$ were found to have a benign tumor on final pathology. While these results are encouraging, given the low quality of existing evidence, current guidelines on the management of complex renal cysts continue to recommend surgery as the mainstay treatment and suggest that the use of active surveillance should be reserved for select patients $[6,16]$.

This study sought out to assess the adoption of active surveillance in Canada and to examine barriers to more widespread use. We found that approximately one third of Canadian urologists stated that they offered active surveillance as a treatment option in greater than $50 \%$ of patients who are diagnosed with a Bosniak III cyst, while only $10 \%$ of urologists offered surveillance in the majority of Bosniak IV cases. Importantly, over $60 \%$ of urologists did not consider or rarely considered active surveillance as a treatment option for a Bosniak IV cyst. Furthermore, the adoption of active surveillance for both Bosniak III and IV cysts was significantly greater among academic urologists compared to non-academic urologists. Likely reflecting the confidence of urologists for active surveillance, a greater proportion of urologists felt that, when offered to a patient, the chance of surveillance being chosen as management strategy was greater among patients diagnosed with a Bosniak III cyst than those with a Bosniak IV cyst.

When respondents were questioned on potential barriers preventing a more widespread use of active surveillance, the most common perceived concerns were [1] the lack of data supporting this strategy in this population, [2] the oncologic safety and benefits of active surveillance and [3] the lack of guidance on how to perform active surveillance and which specific triggers should be used to recommend discontinuation of active surveillance. We asked respondents what patient and tumor characteristics increased their likelihood of recommending active surveillance. As expected, a number of factors seemed to influence the urologist's decision, highlighting the fact that treatment decision for Bosniak III and IV 
cysts is a challenging one. We identified that a personal or familial history of kidney cancer, as well as the patient's treatment preference, influenced the likelihood that a physician would offer active surveillance. Multiple tumor characteristics also seemed to influence the likelihood of offering surveillance, with the most reported features being cyst size, size of nodular component, and presence of cyst wall nodularity. Importantly, the respondents also identified criteria perceived as triggers to offer discontinuation of active surveillance. For Bosniak III, the most common triggers were progression of cyst on imaging from Bosniak III to IV or development of cyst wall nodularity, and worsening or change in the wall or septa enhancement. For Bosniak IV cysts, the most common criteria identified were growth rate of solid component and overall growth of solid component. Interestingly, for both Bosniak III and IV cysts, the growth of the cystic component was not considered by most urologists as being worrisome enough to warrant treatment.

Although this study offers insight into the current management of complex renal cysts in Canada, it is not devoid of limitations. First, the results are based on Canadian urologists' perceptions, and the identified criteria for initiation and discontinuation of active surveillance have never been properly studied. Therefore, the reported use of active surveillance may not necessarily be generalized to all clinicians' real-life practice. The reported patterns of active surveillance may provide a starting point for future studies, but criteria need to be validated before being applied in clinical practice. Second, there might be a selection bias in our cohort, as urologists interested in active surveillance of complex cysts may have responded to the survey more readily.

On the other hand, the study carries several strengths. First, the survey was pilot tested and validated by 20 experts in the field of urology. Second, the response rate to this survey was $24 \%$, which is similar, and even higher than in other Canadian urology surveys $[25,26]$. Third, this study was designed, conducted and reported according to appropriate recommendations for survey research $[19,20]$. Most of the questions were structured in a closed format (binary, ordinal, nominal) in order to lower the bias of the responses.

\section{Conclusions}

This study supports that, despite the lack of high-quality evidence, many Canadian urologists offer active surveillance as an option to patients with complex renal cysts, especially if they have a Bosniak III cyst. However, the lack of sufficient data or guidelines on safety seems to prevent widespread adoption of active surveillance. Prospective studies should be conducted to provide evidence on the oncologic safety, benefits, harms, cost, eligibility criteria, and guidelines for the discontinuation of active surveillance in the management of Bosniak III and IV cysts.

\section{Supplementary information}

Supplementary information accompanies this paper at https://doi.org/10. 1186/s12894-020-00614-5.

Additional file 1. Survey questions.

Additional file 2. Surgical management of choice for a patient with a Bosniak III or IV cyst $(N=131)$.

Additional file 3. Surgical management of complex cysts compared to the surgical management of solid small renal masses $(N=130)$.

Abbreviation

IQR: Interquartile range

\section{Acknowledgements}

The authors would like to thank I'Unité de recherche clinique et épidémiologique of the Centre de Recherche CHUS for their support in the design of the study and the revision of the manuscript.

\section{Authors' contributions}

AF, AT, LL, PDV, and POR conceived the study and the survey. AT and POR collected and analysed the data. FC and POR wrote the manuscript. AF, AT, $\mathrm{BB}, \mathrm{RHB}, \mathrm{AK}, \mathrm{WK}, \mathrm{LL}, \mathrm{ST}$, and PDV reviewed and contributed to the manuscript. All authors read and approved the final manuscript.

\section{Funding}

The study was funded in part by the Canadian Urological Association Scholarship Foundation and the Kidney Cancer Research Network of Canada. POR has a salary support from Fonds de recherche du Québec en Santé. None of the funding bodies had any role in the design of the study, in data collection, in data analysis, or in interpreting the data and writing the manuscript.

\section{Availability of data and materials}

The datasets used and/or analysed during the current study are available from the corresponding author on reasonable request.

\section{Ethics approval and consent to participate}

Ethics approval was obtained from the CIUSSS de l'Estrie - CHUS Research Ethics Board prior to the dissemination of the survey (IRB approval number MP-31-2019-2876). As stated in the introduction and presentation page of the survey, consent was obtained from participants online, as it was implied upon completion of survey questions.

Consent for publication

Not applicable.

\section{Competing interests}

WK is a member of the editorial board of BMC Urology. All other authors declare that they have no competing interests.

\section{Author details}

'Division of Urology, Department of Surgery, Centre Hospitalier Universitaire de Sherbrooke, 3001, 12e avenue N, Sherbrooke, Quebec J1H 5N4, Canada. ${ }^{2}$ Division of Urology, Department of Surgery, Princess Margaret Cancer Centre, University Health Network and the University of Toronto, Toronto, Canada. ${ }^{3}$ Unité de recherche clinique et épidémiologique, Centre de Recherche, Centre Hospitalier Universitaire de Sherbrooke, Sherbrooke, Canada. ${ }^{4}$ Division of Urology, Department of Surgery, Southern Alberta Institute of Urology, Calgary, Canada. ${ }^{5}$ Division of Urology, Department of Surgery, Ottawa Hospital, Ottawa Hospital Research Institute and University of Ottawa, Ottawa, Canada. ${ }^{6}$ Division of Urology, Department of Surgery, Juravinski Hospital, St. Joseph Healthcare, McMaster University, Hamilton, Canada. ${ }^{7}$ Division of Urology, Department of Surgery, McGill University Health Centre, McGill University, Montreal, Canada. ${ }^{8}$ Division of Urology, Department of Surgery, Woodstock Hospital, Woodstock, Canada. 
Received: 16 January 2020 Accepted: 13 April 2020

Published online: 28 April 2020

\section{References}

1. Marumo K, Horiguchi Y, Nakagawa K, Oya M, Ohigashi T, Asakura H, et al. Incidence and growth pattern of simple cysts of the kidney in patients with asymptomatic microscopic hematuria. Int J Urol. 2003;10:63-7.

2. Bosniak M. The current radiological approach to renal cysts. Radiology. 1986; 158:1-10.

3. Bosniak M. Diagnosis and Management of Patients with complicated cystic lesions of the kidney. AJR. 1997;169:819-21.

4. Israel GM, Bosniak MA. An update on the Bosniak renal cyst classification system. Urology. 2005;66:484-9.

5. Bhatt JR, Jewett M, Richard PO, Kawaguchi S, Timilshina N, Evans A, et al. Multilocular cystic renal cell carcinoma: pathological T staging makes no difference to favorable outcomes and should be reclassified. J Urol. 2016; 196:1350-5.

6. Richard PO, Violette PD, Jewett MAS, Pouliot F, Leveridge MJ, So A, et al. CUA guideline on the management of cystic renal lesions. Can Urol Assoc J. 2017;11:E66-73.

7. Schoots IG, Zaccai K, Hunink MG, Verhagen P. Bosniak classification for complex renal cysts reevaluated: a systematic review. J Urol. 2017;198:12-21.

8. Donin NM, Mohan S, Pham H, Chandarana H, Doshi A, Deng F-M, et al. Clinicopathologic outcomes of cystic renal cell carcinoma. Clin Genitourin Cancer. 2015;13:67-70.

9. Gong K, Zhang N, He Z, Zhou L, Lin G, Na Y. Multilocular cystic renal cell carcinoma: an experience of clinical management for 31 cases. J Cancer Res Clin Oncol. 2008;134:433-7.

10. Nassir A, Jollimore J, Gupta R, Bell D, Norman R. Multilocular cystic renal cell carcinoma: a series of 12 cases and review of the literature. Urology. 2002; 60:421-7.

11. Winters BR, Gore JL, Holt SK, Harper JD, Lin DW, Wright JL. Cystic renal cell carcinoma carries an excellent prognosis regardless of tumor size. Urol Oncol. 2015;33:e9-13.

12. Bielsa O, Lloreta J, Gelabert-Mas A. Cystic renal cell carcinoma: pathological features, survival and implications for treatment. Br J Urol. 1998;82:16-20.

13. Corica FA, Iczkowski KA, Cheng L, Zincke H, Blute ML, Wendel A, et al. Cystic renal cell carcinoma is cured by resection: a study of 24 cases with longterm followup. J Urol. 1999;161:408-11.

14. Koga S, Nishikido M, Hayashi T, Matsuya F, Saito Y, Kanetake H. Outcome of surgery in cystic renal cell carcinoma. Urology. 2000;56:67-70.

15. Murad T, Komaiko W, Oyasu R, Bauer K. Multilocular cystic renal cell carcinoma. Am J Clin Pathol. 1991;95:633-7.

16. Ljungberg B, Albiges L, Abu-Ghanem Y, Bensalah K, Dabestani S, FernandezPello S, et al. European Association of Urology Guidelines on Renal Cell Carcinoma: The 2019 Update. Eur Urol. 2019;75(5):799-810.

17. Chandrasekar T, Ahmad A, Fadaak K, Jhaveri K, Bhatt J, Jewett M, et al. Natural history of complex renal cysts: clinical evidence supporting active surveillance. J Urol. 2018;199:633-40.

18. Pruthi D, Liu Q, Kirkpatrick I, Gelfond J, Drachenberg D. Long-term surveillance of complex cystic renal masses and heterogeneity of Bosniak 3 lesions. J Urol. 2018;200:1192-9.

19. Burns KE, Duffett $M$, Kho ME, Meade MO, Adhikari NK, Sinuff T, et al. A guide for the design and conduct of self-administered surveys of clinicians. CMAJ. 2008;179(3):245-52.

20. Eysenbach G. Improving the quality of web surveys: the checklist for reporting results of internet E-surveys (CHERRIES). J Med Internet Res. 2004; 6(3):e34.

21. Bhindi B, Thompson R, Lohse C, Mason R, Frank I, Costello B, et al. The probability of aggressive versus indolent histology based on renal tumor size: implications for surveillance and treatment. Eur Urol. 2018;74:489-97.

22. Finelli A, Ismaila N, Bro B, Durack J, Eggener S, Evans A, et al. Management of small renal masses: American Society of Clinical Oncology clinical practice guideline. J Clin Oncol. 2017;35:668-80.

23. Jewett MA, Mattar K, Basiuk J, Morash CG, Pautler SE, Siemens DR, et al. Active surveillance of small renal masses: progression patterns of early stage kidney cancer. Eur Urol. 2011;60:39-44.

24. Pierorazio PM, Johnson MH, Ball MW, Gorin MA, Trock BJ, Chang P, et al. Five-year analysis of a multi-institutional prospective clinical trial of delayed intervention and surveillance for small renal masses: the DISSRM registry. Eur Urol. 2015;68:408-15.
25. Richard PO, Martin L, Lavallee LT, Violette PD, Komisarenko M, Evans AJ, et al. Identifying the use and barriers to the adoption of renal tumour biopsy in the management of small renal masses. Can Urol Assoc J. 2018; 12(8):260-6.

26. Millar AC, Elterman DS, Goldenberg L, Van Asseldonk B, Curtis A, Jarvi K. A survey of Canadian urologists' opinions and prescribing patterns of testosterone replacement therapy in men on active surveillance for low-risk prostate cancer. Can Urol Assoc J. 2016;10(5-6):181-4.

\section{Publisher's Note}

Springer Nature remains neutral with regard to jurisdictional claims in published maps and institutional affiliations.
Ready to submit your research? Choose BMC and benefit from:

- fast, convenient online submission

- thorough peer review by experienced researchers in your field

- rapid publication on acceptance

- support for research data, including large and complex data types

- gold Open Access which fosters wider collaboration and increased citations

- maximum visibility for your research: over $100 \mathrm{M}$ website views per year

At $\mathrm{BMC}$, research is always in progress.

Learn more biomedcentral.com/submissions 